\title{
Carbon C 14 Ombrabulin
}

National Cancer Institute

\section{Source}

National Cancer Institute. Carbon C 14 Ombrabulin. NCI Thesaurus. Code C90556.

A synthetic water-soluble analogue of combretastatin A4, derived from the South African willow bush (Combretum caffrum), labeled with carbon C 14 with potential antineoplastic activity. The ombrabulin moiety of carbon C 14 ombrabulin binds to the colchicine binding site of endothelial cell tubulin, thereby inhibiting tubulin polymerization and inducing mitotic arrest and apoptosis in endothelial cells. As apoptotic endothelial cells detach from their substrata, tumor blood vessels collapse; the acute disruption of tumor blood flow may result in tumor necrosis. The radioisotope moiety of this agent acts as a radioactive tracer. 